\title{
Sorption of Sulfonamide Antibiotics to Soil Organic Sorbents: Batch Experiments with Model Compounds and Computational Chemistry
}

\author{
J. Schwarz, ${ }^{1,2}$ S. Thiele-Bruhn, ${ }^{3}$ K.-U. Eckhardt, ${ }^{1}$ and H.-R. Schulten ${ }^{1}$ \\ ${ }^{1}$ Institute of Land Use, University of Rostock, Justus-von-Liebig Weg 6, D-18059 Rostock, Germany \\ ${ }^{2}$ Department of Environmental and Soil Chemistry, University of Koblenz/Landau, Fortstrasse 7, D-76829 Landau, Germany \\ ${ }^{3}$ Department of Soil Science, University of Trier, Behringstrasse 21, D-54286 Trier, Germany
}

Correspondence should be addressed to S. Thiele-Bruhn, thiele@uni-trier.de

Received 7 December 2011; Accepted 19 January 2012

Academic Editor: K. Noborio

Copyright (C) 2012 J. Schwarz et al. This is an open access article distributed under the Creative Commons Attribution License, which permits unrestricted use, distribution, and reproduction in any medium, provided the original work is properly cited.

\begin{abstract}
Sorption of the sulfonamide antibiotics sulfanilamide, sulfadimethoxine, and sulfapyridine to model soil organic matter was investigated. Therefore, Fluka humic acid and an enzymatically reacted vanillin oligomer were used in batch experiments at $\mathrm{pH}$ 4.5, 6.0, and 7.5. Sorption of the amphoteric sulfonamides was nonlinear and $\mathrm{pH}$ dependent. At $\mathrm{pH} 4.5$ and 6.0 sorption to both humic acid and oligomer increased in the order sulfanilamide < sulfapyridine < sulfadimethoxine. This was primarily attributed to the sulfonamides' H-bond donor/acceptor properties. Sorption to the oligomer indicated that in addition to $\pi$ - $\pi$ interactions with aromatics phenolic, aldehyde and methoxyl moieties of the oligomer are specific binding sites. Stronger sorption to humic acid than to the oligomer was related to the more complex structure and functional group diversity of humic acid. At $\mathrm{pH} 7.5$ sorption sequence was changed to sulfadimethoxine $<$ sulfanilamide $<$ sulfapyridine, indicating a changed sorption behavior due to different sulfonamide speciation. In part sorption non-reversibility was strong. This was attributed to surface complexation, rate-limiting intra-particle diffusion processes and entrapment of sulfonamides in voids of organic matter. Molecular mechanics $(\mathrm{MM}+)$ computational modeling using a DOM-trimer model confirmed that H-bonding and dipole-dipole interactions are crucial for entrapment of sulfonamides in voids of organic matter.
\end{abstract}

\section{Introduction}

In the past decade, pharmaceutical antibiotics were recognized as emerging soil pollutants. Compounds such as tetracyclines and sulfonamides reach agricultural land mostly through contaminated manure from medicated livestock used as fertilizer $[1,2]$. Pharmaceutical antibiotics are a large group of structurally diverse compound classes that comprise mostly polar and ionizable compounds [3]. Hence, their soil sorption behavior deviates from that of wellstudied hydrophobic organic pollutants. In addition to hydrophobic interactions, antibiotics may sorb to soils via hydrogen bonding, van der Waals forces, cation exchange, cation bridging, and surface complexes $[4,5]$. The sorption of sulfonamides is strongly influenced by $\mathrm{pH}$ and ionic strength [6-8]. Relevant sorption occurs to both soil organic matter (SOM) and soil minerals, that is, clay minerals and pedogenic oxides $[7,9]$. However, as for other compounds sorption is dominated by SOM, and first studies were published that further elucidated the relevant sorption sites and mechanisms [9-11]. It was reported that sulfonamide antibiotics exhibit strong nonlinear sorption to functional groups of SOM through preferred site-specific sorption via hydrogen bonds and van der Waals interactions. In part strong desorption hysteresis and rapid formation of nonextractable residues were reported $[11,12]$ that indicates reaching of an energetically favorable status and inclusion of sulfonamides in voids of soil sorbents. Correlation with the abundance of SOM structural features was used to assign preferred binding sites of sulfonamides to SOM [9-11].

However, sorption chemistry is not easily characterized using complex and heterogeneous natural sorbents such as 
soil. This can be overcome by investigating either separated natural soil constituents such as humic acid or polymers from well-defined phenolic compounds, representing specific sites and functionalities of humic substances that can serve as models to elucidate modes of binding [13]. Phenolic compounds are major building blocks of humic polymers and were found to polymerize to humus-like substances [14]. Additional to experimental evidence, computational chemistry enables to model particulate and dissolved SOM and to calculate important characteristics of soil sorbents [15]. The binding and trapping of biological and anthropogenic compounds was already illustrated with such models using molecular mechanics calculations $[9,16,17]$. Relevant parameters such as van der Waals volumes, total electrostatic forces, the total potential energy, and stabilization energy of xenobiotic-organic matter complexes were calculated and shed new light on experimental results.

The aim of the study presented is to quantify and characterize the sorption of three selected sulfonamide antibiotics to SOM combining experimental results from two selected high-molecular sorbents and computational chemistry. For this purpose, a Fluka humic acid (HA) and an enzymatically reacted vanillin oligomer (VEO) were selected as defined model sorbents for the use in batch experiments while a well-documented soil-dissolved organic matter (DOM) trimer [15] was used as a model of an SOM structure for computational $\mathrm{MM}+$ calculations. More detailed objectives were (i) to determine sorption coefficients and nonlinearity of sorption and desorption, (ii) to investigate the effect of $\mathrm{pH}$ on sorption, and (iii) to investigate the modes of sulfonamide binding at the atomic level with the help of modeled sorption interactions using computational chemistry in order to further explain experimental results.

\section{Materials and Methods}

2.1. Organic Sorbents. Purified humic acid (HA) was obtained from Fluka Biochimika (Buchs, Switzerland). The original composition was changed upon aging by degradation of sugars. The total content of carbon $(44.5 \% \mathrm{C})$, nitrogen $(0.8 \% \mathrm{~N})$, and sulfur $(1.2 \% \mathrm{~S})$ was determined by dry combustion of $2.5 \mathrm{mg}$ dry substance with a CNSanalyzer (VarioEl, Elementar Analysesysteme GmbH, Hanau, Germany).

Vanillin was enzymatically reacted to form an oligomeric substance. For this purpose the enzyme laccase from Tramales versicolor with approximately 50 units $\mathrm{mL}^{-1}$ was used. One unit corresponds to the amount of laccase that converts $1 \mu \mathrm{mol}$ catechol per minute at $\mathrm{pH} 4.5$ and $25^{\circ} \mathrm{C}$. To $1 \mathrm{~g}$ of vanillin $10 \mathrm{~mL}$ of laccase solution in formate buffer $(\mathrm{pH} 4.5)$ was added. After a reaction time of $24 \mathrm{~h}$ at $21^{\circ} \mathrm{C}$ in the dark, the reaction was restarted by the addition of $10 \mathrm{~mL}$ fresh laccase solution. The solution was allowed to evaporate, and the precipitate was cleaned up through quintuplicate repeated methanol washing. The elemental composition of the oligomeric substance was $60.1 \% \mathrm{C}, 0.2 \% \mathrm{~N}$, and $0.02 \%$ $\mathrm{S}$. Residing $\mathrm{N}$ and $\mathrm{S}$ was attributed to enzyme protein that resisted methanol washing. In the presence of laccase, vanillin (see Figure 1 compound A) loses an electron and a hydrogen atom at the hydroxyl group and forms radicals [13]. The two mesomeric structures of these radicals are shown in Figure 1, compounds B and C. These highly reactive intermediates recombine to form dimeric structures. Two likely products of this recombination are displayed in Figure 1, compounds C and D. Further recombination reactions of the free radicals are likely that include monomers, dimers, and higher molecular products and which result in vanillin enzymatic oligomer (VEO) structures.

2.2. Chemicals. The antibiotic sulfanilamide (SAA; 4 -amino benzenes-ulfonamide) was obtained from Riedel-de Haën (Seelze, Germany). Sulfadimethoxine (SDT; 4-amino-N-[2,6dimethoxy-4-pyrimidinyl]benzenesulfonamide), vanillin (4hydroxy-3-methoxybenzaldehyde), and the enzyme laccase from Tramales versicolor were purchased from Fluka Biochimika (Buchs, Switzerland). Sulfapyridine (SPY; 4-amino$\mathrm{N}$-(2-pyridinyl)benzenesulfonamide) was purchased from Sigma-Aldrich (Steinheim, Germany). See Table 1 for the structures and physicochemical data of the sulfonamide antibiotics. All substances and solvents that were used were of p.a. or HPLC gradient grade quality. Hydrogen bond donator and acceptor properties were calculated using Advanced Chemistry Development (ACD/Labs) software V8.14 for Solaris (1994-2006 ACD/Labs, Toronto, Canada).

2.3. Batch Experiments. All samples were prepared in triplicate. For each replicate $10 \mathrm{mg}$ of HA and $20 \mathrm{mg}$ of VEO, respectively, were weighed into $30-\mathrm{mL}$ glass centrifuge tubes and spiked with $5 \mathrm{~mL}$ or $10 \mathrm{~mL}$ standard solution containing one of the three sulfonamides. The sorption-desorption process was investigated at three different $\mathrm{pH}$ values, covering the typical $\mathrm{pH}$ range in agricultural soils, in order to investigate the sorption of the anionic, neutral, and cationic sulfonamide species. For a $\mathrm{pH}$ of 4.5 a sodium formateformic acid buffer $(0.025 \mathrm{M})$ was used and a phosphate buffer $\left(0.2 \mathrm{M} \mathrm{NaH}_{2} \mathrm{PO}_{4} / \mathrm{Na}_{2} \mathrm{HPO}_{4}\right)$ for the $\mathrm{pH}$ values of 6.0 and 7.5. The sorption to VEO and HA was investigated with eight and five concentrations, respectively, ranging from 0.08 to $1.2 \mu \mathrm{mol} \mathrm{mL} \mathrm{m}^{-1}$. The sorption step was followed by a desorption step, for which purpose the equilibrium solution was replaced with the corresponding buffer solution without sulfonamide. As a third step, a subsequent extraction with $1 \mathrm{~mL}$ methanol was carried out. For each step, the samples were agitated on a horizontal shaker at 200 RPM for $20 \mathrm{~h}$ at $21^{\circ} \mathrm{C}$ in the dark prior to $50 \mathrm{~min}$ centrifugation at $1930 \mathrm{~g}$. The supernatant was removed, and aliquots of the equilibrium solutions and methanol extracts, respectively, were directly transferred into HPLC vials.

2.4. HPLC Analysis. For sulfonamide analysis, an HP 1050/Agilent 1100 series HPLC system with diode array detector (Agilent G1315B, Böblingen, Germany) operated at $260 \mathrm{~nm}$ was used. A C18 reversed phase column (MachereyNagel, Düren, Germany) $250 \times 4.6 \mathrm{~mm}, 120-5 \mu \mathrm{m}$, served as stationary phase. As mobile phase a gradient of methanol and $0.01 \mathrm{M} \mathrm{H}_{3} \mathrm{PO}_{4}$ was used at a flow rate of $1 \mathrm{~mL} \mathrm{~min}^{-1}$. 
<smiles>COc1cc(C=O)ccc1OCCCOc1cc(C=O)ccc1O</smiles>

B<smiles>COc1cc(C=O)ccc1Oc1cc(C=O)cc(OC)c1O</smiles>

D

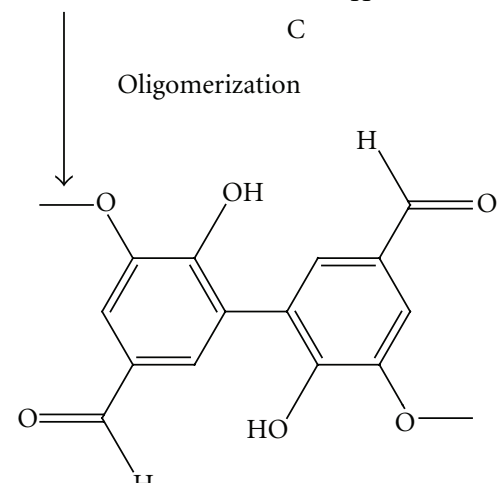

E

Figure 1: Reaction pathway scheme for the oligomerization of vanillin (compound A).

TABLE 1: Selected physical-chemical properties from the literature cited in [3], $\mathrm{p} K_{\mathrm{a}}$ from [18], and molecular structures of the selected sulfonamides.

\begin{tabular}{|c|c|c|}
\hline $\begin{array}{l}\text { Compound CAS no. } \\
\text { molecular weight }\end{array}$ & Elemental composition, structural formula & $\begin{array}{l}\text { Physicochemical } \\
\text { properties }\end{array}$ \\
\hline $\begin{array}{l}\text { Sulfanilamide (SAA) } \\
63-74-1 \\
172.20 \mathrm{~g} \mathrm{~mol}^{-1}\end{array}$ & $\mathrm{C}_{6} \mathrm{H}_{8} \mathrm{~N}_{2} \mathrm{O}_{2} \mathrm{~S}$ & $\begin{array}{c}\log K_{\mathrm{ow}}-0.62 \\
\mathrm{~S}^{\mathrm{a}} 7500 \mathrm{mg} \mathrm{L} \mathrm{L}^{-1} \\
\mathrm{p} k_{\mathrm{a}, 1} 1.94 \\
\mathrm{p} k_{\mathrm{a}, 2} 10.67\end{array}$ \\
\hline $\begin{array}{l}\text { Sulfapyridine (SPY) } \\
144-83-2 \\
249.29 \mathrm{~g} \mathrm{~mol}^{-1}\end{array}$ & $\begin{array}{r}\mathrm{C}_{11} \mathrm{H}_{11} \mathrm{~N}_{3} \mathrm{O}_{2} \mathrm{~S} \\
\end{array}$ & $\begin{array}{l}\log K_{\mathrm{ow}} 0.35 \\
\mathrm{~S} 268 \mathrm{mg} \mathrm{L}^{-1} \\
\mathrm{p} k_{\mathrm{a}, 1} 2.72 \\
\mathrm{p} k_{\mathrm{a}, 2} 8.40\end{array}$ \\
\hline $\begin{array}{l}\text { Sulfadimethoxine (SDT) } \\
122-11-2 \\
310.33 \mathrm{~g} \mathrm{~mol}^{-1}\end{array}$ & $\mathrm{C}_{12} \mathrm{H}_{14} \mathrm{~N}_{4} \mathrm{O}_{4} \mathrm{~S}$ & $\begin{array}{l}\log K_{\mathrm{ow}} 1.63 \\
\mathrm{~S} 343 \mathrm{mg} \mathrm{L}^{-1} \\
\mathrm{p} k_{\mathrm{a}, 1} 2.12 \\
\mathrm{p} k_{\mathrm{a}, 2} 7.28\end{array}$ \\
\hline
\end{tabular}


Injection volumes were $10 \mu \mathrm{L}$ and the sulfonamides were quantified by using external standards. Details on detection limits and recovery rates were published elsewhere [19].

2.5. Pyrolysis-Field Ionization Mass Spectrometry. A modified Finnigan MAT 731 high-performance mass spectrometer (Finnigan, Bremen, Germany) was used for pyrolysis-field ionization mass spectrometry (Py-FIMS) of HA and VEO. For analysis, about $3 \mathrm{mg}$ of sample was thermally degraded in the ion source by heating the sample in high vacuum from 110 to $700^{\circ} \mathrm{C}$ in steps of $10^{\circ} \mathrm{C} \mathrm{s}^{-1}$. In total, 60 magnetic scans were recorded in the mass range of $\mathrm{m} / \mathrm{z} 15$ to $\mathrm{m} / \mathrm{z} 900$ (single spectra). These were combined to obtain one thermogram of total ion intensity (TII) and an averaged mass spectrum. For further details on the Py-FIMS methodology and the statistical evaluation of TII data, see [20].

2.6. Mathematical Description of Sorption Data. Experimental sorption data were fitted with the Statistica 6.0 software for nonlinear regression (StatSoft Inc., Tulsa, OK, USA) that uses a Levenberg-Marquardt algorithm for the nonlinear least squares problem. The precision of the curve-fit was assessed from the determination coefficient $R^{2}$ and the standard error (SE) of each parameter. The Freundlich equation (1) was fitted to the experimental data as it better represents sorbent heterogeneity than, for example, the Langmuir isotherm:

$$
C_{s}=K_{f} \times c_{\mathrm{aq}}^{n}
$$

In the Freundlich equation, $C_{s}$ is the total sorbate concentration associated with the sorbent $(\mu \mathrm{mol} / \mathrm{g}), c_{\mathrm{aq}}^{n}$ is the concentration in the aqueous solution $\left(\mu \mathrm{mol} \mathrm{mL}^{-1}\right), K_{f}$ is the Freundlich sorption coefficient $\left(\mu \mathrm{mol}^{1-n} \mathrm{~L}^{n} \mathrm{~kg}^{-1}\right)$, and the exponent $n$ is the measure of nonlinearity.

As a measure of sorption hysteresis, the thermodynamic index of irreversibility (TII) was calculated [21]. However, to not confuse this parameter with the total ion intensity (TII) of mass spectrometric analysis, it was termed here as $1-H$ :

$$
1-H=1-\frac{n_{\text {sorb }}}{n_{\text {desorb }}} \text {. }
$$

2.7. Computational Modeling. For model design, structural modeling, geometry optimization, chemical interaction studies, and molecular mechanics calculations (MM+), the HyperChem 7.5 software package, version 2002 (Hypercube Inc., Gainesville, FL), was used. The ChemPlus (ver. 3.1) software was utilized for calculating molecular properties of the DOM trimer model employed as the host structure in this study. The MM+ is the method of choice for computational simulation of large molecules [22]. Details of the geometry optimization and energy minimization process using MM+ and our modeling approach have been reviewed elsewhere [15].

\section{Results and Discussion}

3.1. Characterization of the Different Sorbents by Py-FIMS. Two model sorbents were used in batch experiments to eluci- date the sites and mechanisms of sulfonamide sorption to SOM. For this purpose, the chemical composition was characterized using Py-FIMS. The Py-FI mass spectrum of the pale yellow VEO that was obtained by enzyme-catalyzed oxidative coupling of the substituted phenolic monomer showed several distinct signals (Figure 2(a)). The most intense signal at $m / z 302$ corresponded to the assumed dimeric structures in Figure 1, C and D. Tetramer structures gave a small signal at $m / z 604$, and bound vanillin was determined at $m / z 152$. The major mass loss by pyrolysis was distributed over a temperature range from 100 to $500^{\circ} \mathrm{C}$, which indicated that a complex structure with a diverse crosslinking was formed. Compared to the simple VEO structure, the Py-FI mass spectrum of the second model sorbent, a Fluka humic acid (HA), was much more complex. The mass loss by pyrolysis of HA began at a higher temperature compared to VEO and ranged from 150 to $575^{\circ} \mathrm{C}$, which shows the larger stability of the organic matter bound within the high molecular structure. The mass signals extended over the whole mass range recorded (Figure 2(b)). Assignment of marker signals to compound classes was done according to [23] and revealed that HA comprised the following fractions (\% of TII in parentheses): alkyl aromatics (11.9) > lignin dimers (11.2) $>$ sterols (10.3) > fatty acids n-C16 to n-C34 (9.9) > alkanes, alkenes, n-alkyl esters, and n-alkyl diesters (9.0) > phenols and lignin monomers (5.9) > N-containing compounds (3.7) $>$ carbohydrates $(2.7)>$ peptides $(2.4)>$ suberin $(1.0)$. This indicated clear differences between the two sorbents, while the HA chemical composition fairly matched that of the SOM of a long-term fertilized Chernozem soil [9]. However, it is well known that Fluka HA has several features different to SOM, but, regarding the aims of this study, it appears a sufficient model for complex organic geosorbents.

3.2. Sulfonamide Sorption to Model Compounds. The sorption isotherms of SAA, SPY and SDT to HA and VEO at $\mathrm{pH}$ 4.5 are shown in Figure 3. The sorption was clearly nonlinear and best fit using the Freundlich isotherm $\left(R^{2} 0.91\right.$ to 1.00$)$ with the Freundlich exponent $(n)$ ranging from 0.45 to 0.87 (Table 2). This indicates site-specific sorption and resulting sorption heterogeneity of sulfonamides in the presence of organic matter. For both sorbents, the sorption coefficient $K_{f}$ at $\mathrm{pH} 4.5$ increased in the order SAA $<$ SPY $<$ SDT, in which sequence confirms previous findings $[9,19]$. However, $K_{d}$ and $K_{f}$ values of sulfonamide sorption that were reviewed from the literature range from 0.27 to 7.30 for whole soils and particle size fractions [3] and are substantially smaller than $K_{f}$ of 20 to 497 determined for sorption to HA and VEO. This corresponds to the differences between the coefficients of sorption to soil versus sorption to SOM that were reported for other antibiotic compounds $[4,11]$. It shows that SOM is most important for the sorption of sulfonamide antibiotics, although sorption to soil minerals is also relevant. Sorption of sulfonamides to clay minerals at a $\mathrm{pH}$ similar to that used in this study reached $K_{d}\left(\mathrm{~L} \mathrm{~kg}^{-1}\right)$ up to a range of 30 [7].

The extent of sulfonamide sorption to VEO was substantial. The results suggest that in addition to $\pi-\pi$ interactions with the aromatic ring the phenolic, aldehyde, and methoxyl 


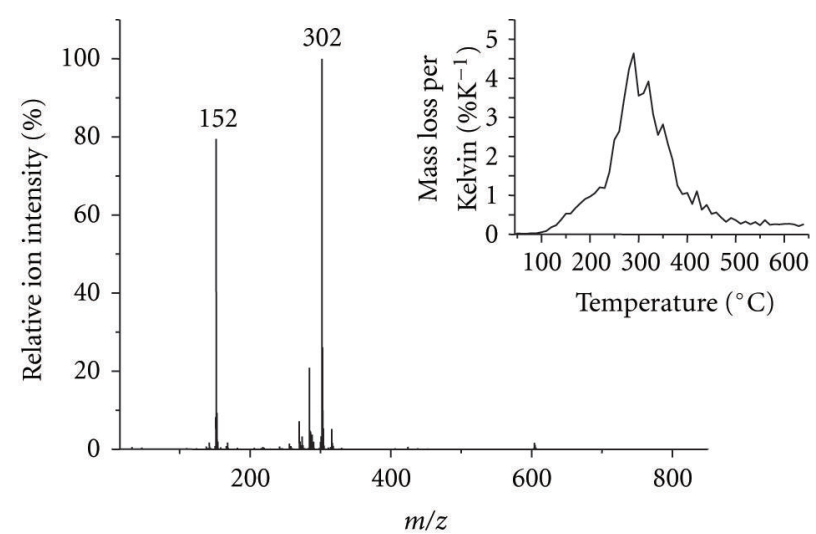

(a)

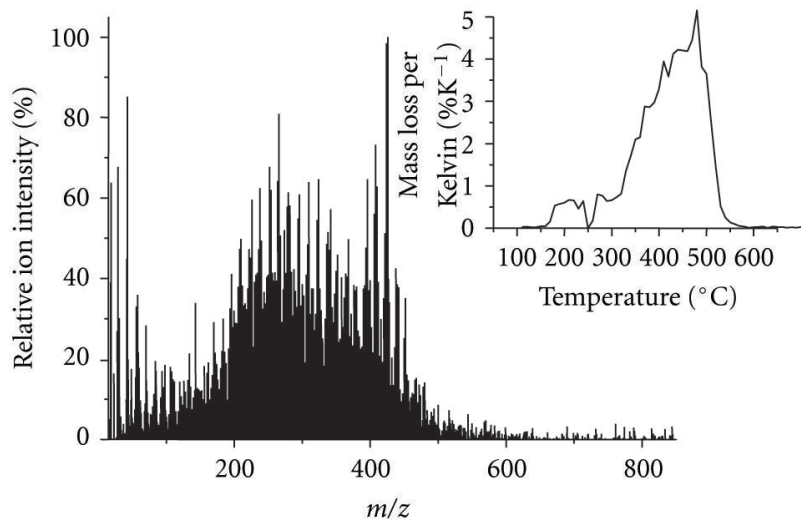

(b)

FIgURe 2: Py-FI mass spectra for model sorbents (a) VEO and (b) HA.

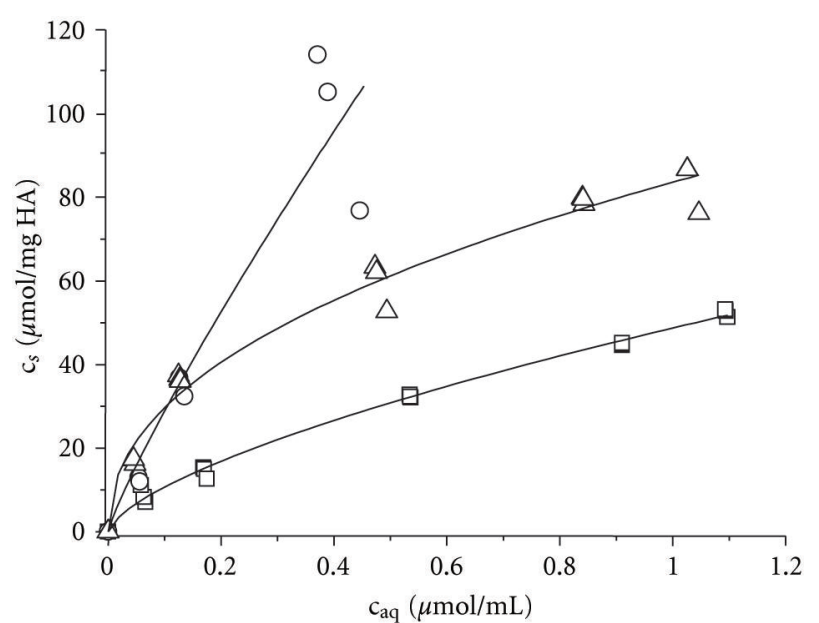

(a)

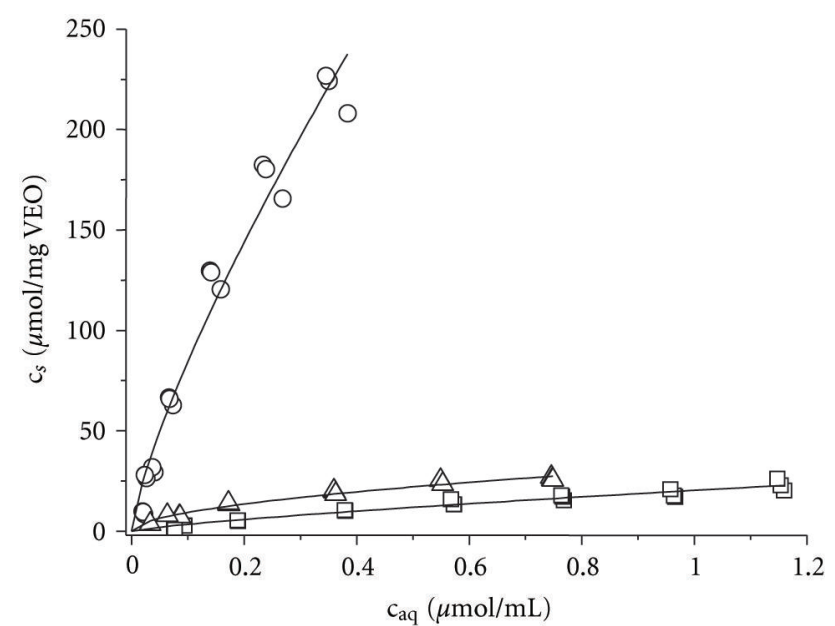

(b)

FIGURE 3: Isotherms for the sorption (a) to HA and (b) to VEO of the sulfonamides SAA ( $\square)$, SPY $(\triangle)$ and $\operatorname{SDT}(\bigcirc)$ at a pH of 4.5 in a formate-formic acid buffer.

moieties of VEO (Figure 1) are among the preferred specific binding sites of sulfonamide antibiotics sorbed to SOM. This is in accordance with findings of [11] for garden waste compost, pig manure, and leonardite humic acid. However, sorption to VEO was clearly smaller compared to HA, which can be seen from the $K_{f}$ values at all $\mathrm{pH}$ values investigated (Table 2). This was expected because of the fewer constituents and lower complexity of the molecular structure of VEO (Figure 2). The polymeric HA additionally comprises ketonic, enolic, alcoholic, and $\mathrm{N}$-alkylic functionalities that were shown to significantly contribute to the specific sorption of sulfonamide antibiotics $[9,11]$. This together with the larger complexity of HA, offering voids and pores for sorbate inclusion, explains the stronger sulfonamide sorption to HA as opposed to VEO. In contrast to all other sulfonamide-pH combinations, the $K_{f}$ of SDT sorption to VEO at $\mathrm{pH} 4.5$ was twice larger compared to HA whose result is not well understood.

An increase of the $\mathrm{pH}$ of the equilibrium solution from 4.5 to 6.0 and 7.5 clearly affected the sorption of all three sulfonamides in the presence of both organic sorbents (Table 2), while best fit was in all cases achieved with the nonlinear Freundlich isotherm. From pH 4.5 to 6.0 the extent of sorption declined, and the $K_{f}$ values were lower by an average factor of 2. At pH 7.5 $K_{f}$ values of SAA and SPY were nearly similar to those at $\mathrm{pH} 4.5$. In contrast, the sorption of SDT to HA and VEO further declined, and $K_{f}$ values were smallest at $\mathrm{pH}$ 7.5. The sequence of the $K_{f}$ values of the three sulfonamides was similar at both $\mathrm{pH} 4.5$ and 6.0, but it changed to SPY $>$ SAA $\geq$ SDT at $\mathrm{pH}$ 7.5.

These findings were attributed to two major factors. First, sulfonamides can exist as four different species in aqueous solution, a cation, a neutral species, a zwitterion, and an acid anion, depending on the $\mathrm{pH}$ of the matrix. Speciation of the sulfonamides was calculated using the Hägg diagram with data from [18]. To account for the accumulation of hydronium ions at the sorbent surface at acidic $\mathrm{pH}$, the $\mathrm{pH}$ was corrected by two units according to [24]. At pH 6.0 all three sulfonamides were basically neutral, while at $\mathrm{pH}$ 4.5 considerable portions of SAA, SDT, and especially SPY 
TABle 2: Parameters of the Freundlich equation describing the sorption and desorption of the sulfonamides SAA, SPY, and SDT to Fluka humic acid (HA) and a vanillin enzymatic oligomer structure (VEO) at different $\mathrm{pH}$ values.

\begin{tabular}{|c|c|c|c|c|c|c|c|c|c|c|c|c|}
\hline \multirow[b]{2}{*}{$\mathrm{pH}$} & \multicolumn{5}{|c|}{ Sorption } & \multicolumn{7}{|c|}{ Desorption } \\
\hline & $K_{f}$ & Error & $n$ & Error & $R^{2}$ & & $K_{f}$ & Error & $n$ & Error & $R^{2}$ & $1-H$ \\
\hline & & & & & & $\mathrm{HA}$ & & & & & & \\
\hline & & & & & & SAA & & & & & & \\
\hline 4.5 & 49 & 0.52 & 0.66 & 0.02 & 1.00 & & 180 & 15 & 0.68 & 0.04 & 0.99 & -0.03 \\
\hline 6.0 & 30 & 0.63 & 0.56 & 0.04 & 0.98 & & 89 & 15 & 0.54 & 0.08 & 0.96 & 0.04 \\
\hline \multirow[t]{2}{*}{7.5} & 48 & 0.84 & 0.50 & 0.02 & 1.00 & & 140 & 37 & 0.50 & 0.12 & 0.94 & 0.00 \\
\hline & & & & & & SPY & & & & & & \\
\hline 4.5 & 84 & 1.7 & 0.45 & 0.03 & 0.98 & & 297 & 15 & 0.60 & 0.03 & 0.99 & -0.33 \\
\hline 6.0 & 44 & 0.66 & 0.50 & 0.02 & 0.99 & & 291 & 39 & 0.87 & 0.08 & 0.97 & -0.74 \\
\hline \multirow[t]{2}{*}{7.5} & 66 & 1.4 & 0.49 & 0.03 & 0.99 & & 219 & 23 & 0.58 & 0.05 & 0.98 & -0.18 \\
\hline & & & & & & SDT & & & & & & \\
\hline 4.5 & 211 & 37 & 0.87 & 0.15 & 0.91 & & 656 & 36 & 0.98 & 0.05 & 0.99 & -0.13 \\
\hline 6.0 & 124 & 12 & 1.01 & 0.10 & 0.97 & & 533 & 12 & 0.97 & 0.03 & 1.00 & 0.04 \\
\hline \multirow[t]{3}{*}{7.5} & 37 & 2.9 & 0.26 & 0.08 & 0.76 & & 95 & 14 & 0.39 & 0.05 & 0.93 & -0.50 \\
\hline & & & & & & VEO & & & & & & \\
\hline & & & & & & SAA & & & & & & \\
\hline 4.5 & 20 & 0.50 & 0.78 & 0.05 & 0.96 & & 252 & 36 & 0.82 & 0.05 & 0.97 & -0.05 \\
\hline 6.0 & 11 & 0.52 & 1.16 & 0.14 & 0.91 & & 53 & 11 & 0.72 & 0.10 & 0.86 & 0.38 \\
\hline \multirow[t]{2}{*}{7.5} & 21 & 0.89 & 0.68 & 0.07 & 0.94 & & 67 & 7.6 & 0.56 & 0.05 & 0.97 & 0.18 \\
\hline & & & & & & SPY & & & & & & \\
\hline 4.5 & 32 & 0.83 & 0.54 & 0.02 & 0.98 & & 265 & 12 & 0.68 & 0.02 & 1.00 & -0.26 \\
\hline 6.0 & 29 & 1.5 & 0.71 & 0.10 & 0.86 & & 265 & 24 & 0.96 & 0.05 & 0.97 & -0.35 \\
\hline \multirow[t]{2}{*}{7.5} & 38 & 0.91 & 0.74 & 0.04 & 0.98 & & 293 & 20 & 0.93 & 0.04 & 0.98 & -0.26 \\
\hline & & & & & & SDT & & & & & & \\
\hline 4.5 & 497 & 34 & 0.77 & 0.05 & 0.97 & & 1152 & 67 & 0.82 & 0.03 & 0.99 & -0.06 \\
\hline 6.0 & 56 & 6.6 & 0.72 & 0.10 & 0.88 & & 550 & 23 & 1.06 & 0.04 & 0.99 & -0.47 \\
\hline 7.5 & 22 & 0.46 & 0.54 & 0.03 & 0.97 & & 30 & 15 & 0.21 & 0.17 & 0.74 & 0.61 \\
\hline
\end{tabular}

TABLE 3: Speciation data for the sulfonamides SAA, SPY, and SDT at the examined $\mathrm{pH}$ values (data calculated using $\mathrm{p} K_{\mathrm{a}}$ values from [18].

\begin{tabular}{cccccc}
\hline & $\mathrm{pH}$ & Cation & Neutral & Anion & Zwitterion \\
\hline \multirow{3}{*}{ SAA } & 4.5 & 21.59 & 78.40 & 0 & 0.01 \\
& 6.0 & 0.86 & 99.10 & 0 & 0.01 \\
& 7.5 & 0.02 & 99.90 & 0.07 & 0.01 \\
\multirow{3}{*}{ SPY } & 4.5 & 62.40 & 37.51 & 0.01 & 0.08 \\
& 6.0 & 4.96 & 94.56 & 0.40 & 0.08 \\
& 7.5 & 0.10 & 88.65 & 11.18 & 0.07 \\
\multirow{3}{*}{ SDT } & 4.5 & 29.42 & 70.23 & 0.16 & 0.19 \\
& 6.0 & 1.13 & 93.70 & 4.99 & 0.18 \\
& 7.5 & 0.03 & 37.50 & 62.40 & 0.07 \\
\hline
\end{tabular}

were cationic (Table 3). The formation of anionic species was dominant for SDT at $\mathrm{pH}$ 7.5. The zwitterionic fraction was negligible with $<0.2 \%$ at all $\mathrm{pH}$ values. The results show that the sorption of cationic species was superior to the sorption of neutral and anionic species, which is in accordance with findings from [6-8]. The cationic species most probably interacted with the organic sorbents through ion exchange, while for neutral species hydrophobic partitioning and nonbonding interactions such as van der Waals forces and hydrogen bridging and for acid anions multivalent cation bridging are proposed [7, 9]. A second factor that probably governed sulfonamide sorption was the influence from different buffers, that is, formate-formic acid buffer for $\mathrm{pH}$ 4.5 and phosphate buffer in samples with $\mathrm{pH} 6.0$ and 7.5. Phosphate is known to effectively compete with organic anions for sorption sites $[25,26]$ which should be relevant for anionic SDT species as well. Correspondingly the sorption of SDT at pH 7.5 was especially small. Furthermore, the ionic strength of the phosphate buffer used was smaller than that of the formate-formic acid buffer. Neutral molecules often show a reduced sorption at smaller salt concentrations [27], whose effect, however, is subordinate for polar chemicals. In addition to the effect from speciation, this contributes to explain the stronger sorption of all three sulfonamides at $\mathrm{pH}$ 4.5 compared to $\mathrm{pH} 6.0$.

The increase in sorption of SAA and SPY from $\mathrm{pH} 6.0$ to 7.5 followed the increase in effective exchange capacity 
of the sorbents (data not shown). Both sulfonamides were mostly present as neutral molecules while the anionic fraction was small with at maximum $11.2 \%$ of SPY at $\mathrm{pH} 7.5$ (Table 3). This shows that the effect of $\mathrm{pH}$ on sulfonamide sorption depends on the compound specific speciation and cannot be generalised for all sulfonamides.

The sorption nonlinearity tended to decline from $\mathrm{pH} 4.5$ to 6.0 with the Freundlich exponent $n$ slightly increasing by an average factor of 1.1, while on average of all samples $n$ was smallest at pH 7.5 (Table 2). Although the $\mathrm{pH}$-dependent changes of $n$ were not consistent for all three sulfonamides, they tend to confirm the supposed sorption mechanisms. Differences in sorption nonlinearity indicated slightly larger sorption specificity and heterogeneity of the ionic and especially of the anionic species and lesser specificity of the neutral sulfonamide molecules. Neutral molecules may in part interact with the sorbents through partitioning and nonbonding forces such as hydrogen bonds.

Hydrogen bonding is assumed to be a main binding mechanism of sulfonamides. All three sulfonamides are able to donate two hydrogen bonds, while SDT can act as an acceptor for eight hydrogen bonds followed by SPY (five) and SAA (four). Thus, sorption was expected to follow this sequence, which was confirmed by the batch experiments. The sequence of experimental $K_{f}$ was different at $\mathrm{pH}$ 7.5, when a substantial fraction of SDT was anionic but not when the anionic fraction was as low as $11.2 \%$ as it was calculated for SPY (Table 3).

3.3. Desorption and Extractability of Sulfonamides from Model Sorbents. Isotherms of desorption from HA and VEO are shown in Figure 4. It becomes apparent that the overall nonlinearity of the isotherms was not changed in the desorption step. Corresponding to the results from the sorption step, the $K_{f}$ values increased in the sequence SAA $<\mathrm{SPY}<\mathrm{SDT}(\mathrm{pH}$ 4.5 and 6.0) and SDT $<$ SAA $<$ SPY ( $\mathrm{pH} 7.5)$, respectively (Table 2). The $K_{f}$ values were on average by a factor of five larger than the respective $K_{f}$ values of sorption: This factor gradually varied with $\mathrm{pH}$ from $6.3(\mathrm{pH} 6.0)$ to $5.6(\mathrm{pH} 4.5)$ and $3.5(\mathrm{pH} 7.5)$. In total, this indicates considerable sorption non-reversibility and hysteresis which is slightly varied depending on the sulfonamide speciation and underlying sorption mechanisms. Hysteresis was larger for neutral (at $\mathrm{pH}$ 6.0) compared to ionic species (at $\mathrm{pH} 4.5$ and 7.5).

Following the sorption and desorption step, samples were additionally extracted with methanol. According to $[28,29]$, the methanol extract indicates the total desorbable concentration of a compound. Since the sulfonamides were largely removed during sorption and desorption, $\leq 3 \%$ of the spiking concentration of SAA and SPY at all $\mathrm{pH}$ values was extracted with methanol (data not shown). However, considerable fractions of SDT were not desorbed at $\mathrm{pH} 4.5$ and 6.0 , and thus $43 \%(\mathrm{pH} 4.5)$ and $34 \%(\mathrm{pH} 6.0)$ of the spiking concentrations were methanol extracted. Similar values as for HA were determined for the methanol extraction of VEO. The sulfonamide fractions residing after methanol extraction ranged from 0.2 to $0.8 \%$ of the spiking concentration, while the residual concentration of SDT at pH 4.5 was considerably

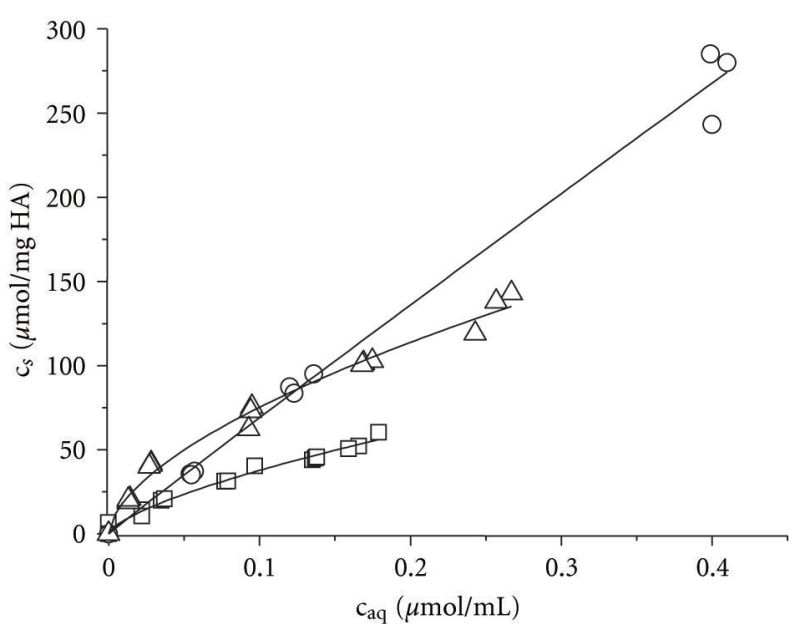

(a)

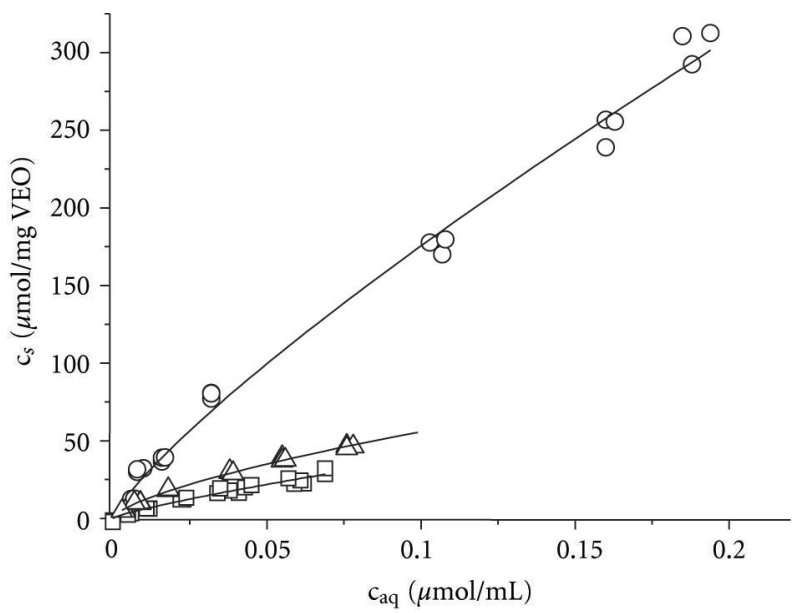

(b)

Figure 4: Isotherms for the desorption (a) from HA and (b) from VEO of the sulfonamides SAA $(\square)$, SPY $(\triangle)$, and SDT $(\bigcirc)$ at a $\mathrm{pH}$ of 4.5 in a formate-formic acid buffer.

larger with $12 \%$ in the presence of VEO. Fixation of nonextractable residues was attributed to surface complexation and rate-limiting intra- and interparticle diffusion processes $[30,31]$ and irreversible chemical binding to the organic macromolecules [32].

3.4. Chemical Modeling for Interactions of Antibiotics with Soil Organic Matter. For molecular modeling a trimer of a previously presented and recognized DOM model [15, 33] was used. It was modeled with a water content of approximately $3 \%$ which is an average value for air-dried samples. The elemental and molecular composition of the organic matter model was accumulated from experimental data (elemental composition in Table 4) and is well within the range of the organic matter composition determined in this study. The DOM trimer host molecule is depicted in Figure 5(a) and comprises three crosslinked identical units with $448 \mathrm{C}$ atoms each (total $1344 \mathrm{C}$ atoms). The DOM trimer model, a host molecule with a wide distribution 
TABle 4: Atomic, molecular, and energetic properties of the modeled dissolved organic matter (DOM) trimer and the complexes with sulfanilamide (SAA), sulfapyridine (SPY), and sulfadimethoxine (SDT).

\begin{tabular}{lcccc}
\hline & DOM trimer & DOM trimer + SAA & DOM trimer + SPY & DOM trimer + SDT \\
\hline Elemental composition & $\mathrm{C}_{1344} \mathrm{H}_{1482}$ & $\mathrm{C}_{1350} \mathrm{H}_{1490}$ & $\mathrm{C}_{1355} \mathrm{H}_{1493}$ & $\mathrm{C}_{1356} \mathrm{H}_{1496}$ \\
& $\mathrm{O}_{918} \mathrm{~N}_{45} \mathrm{~S}_{6}$ & $\mathrm{O}_{920} \mathrm{~N}_{47} \mathrm{~S}_{7}$ & $\mathrm{O}_{920} \mathrm{~N}_{48} \mathrm{~S}_{7}$ & $\mathrm{O}_{922} \mathrm{~N}_{49} \mathrm{~S}_{7}$ \\
Molecular weight $\left(\mathrm{g} \mathrm{mol}^{-1}\right)$ & $33,146.59$ & $33,318.79$ & $33,396.40$ & $33,456.91$ \\
Solvent-acces. surface $\left(\mathrm{nm}^{2}\right)$ & $1,200.22$ & 534.34 & 534.61 & 553.05 \\
Solvent-acces. volume $\left(\mathrm{nm}^{3}\right)$ & $4,841.66$ & $3,176.64$ & $3,012.53$ & $3,171.13$ \\
Van der Waals surface $\left(\mathrm{nm}^{2}\right)$ & $2,733.07$ & $1,021.31$ & $1,017.66$ & $1,049.63$ \\
Van der Waals volume $\left(\mathrm{nm}^{3}\right)$ & $2,510.76$ & $1,510.36$ & $1,551.46$ & $1,510.97$ \\
Bond $\left(\mathrm{kJ} \mathrm{mol}^{-1}\right)$ & $1,143.71$ & $1,050.49$ & $1,141.95$ & $1,145.36$ \\
Angle $\left(\mathrm{kJ} \mathrm{mol}{ }^{-1}\right)$ & $6,897.28$ & $6,921.12$ & $6,914.56$ & $6,909.08$ \\
Dihedral $\left(\mathrm{kJ} \mathrm{mol}^{-1}\right)$ & $4,070.21$ & $3,966.98$ & $4,068.69$ & $3,042.17$ \\
Van der Waals forces $\left(\mathrm{kJ} \mathrm{mol}^{-1}\right)$ & $3,685.84$ & $3,717.60$ & 21.631 .52 & $3,640.83$ \\
Stretch-bend $\left(\mathrm{kJ} \mathrm{mol}^{-1}\right)$ & 221.28 & 221.18 & $-5,09$ & 219.24 \\
Electrostatic forces $\left(\mathrm{kJ} \mathrm{mol}^{-1}\right)$ & $-5,574.18$ & $-5,631.83$ & $10,395.63$ & $-5,544.30$ \\
Total potential energy $\left(\mathrm{kJ} \mathrm{mol}^{-1}\right)$ & $10,444.14$ & $10,245.54$ & -48.51 & $10,412.38$ \\
Stabilization energy $\left(\mathrm{kJ} \mathrm{mol}^{-1}\right)$ & 0 & -198.60 & & -31.76 \\
\hline
\end{tabular}

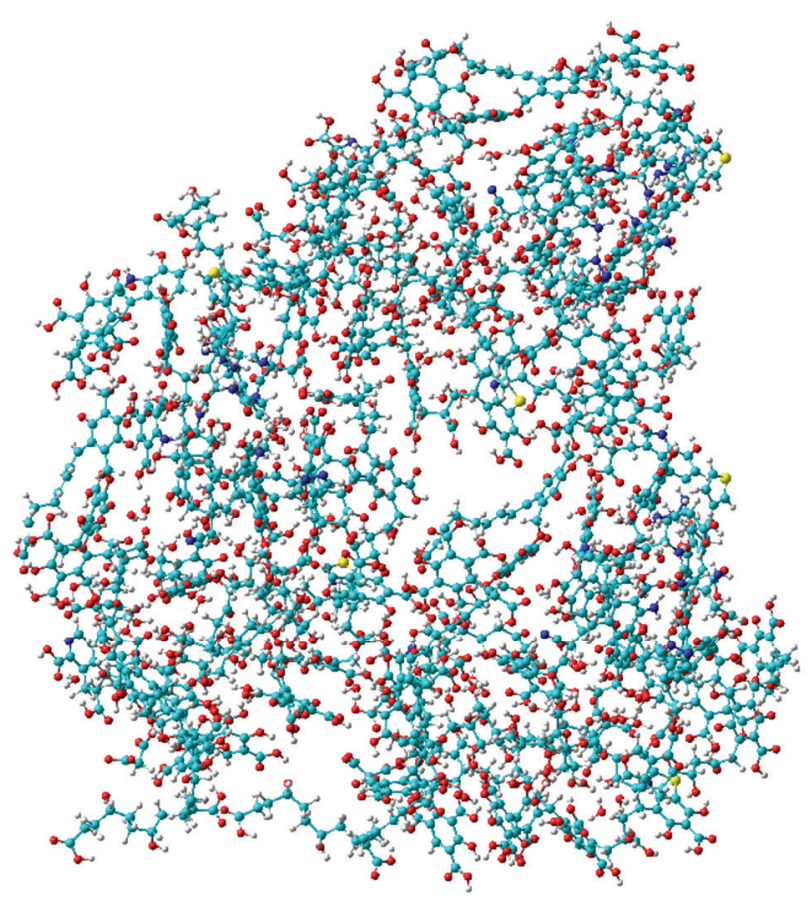

(a) DOM trimer

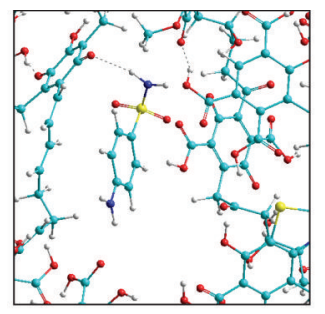

(b)

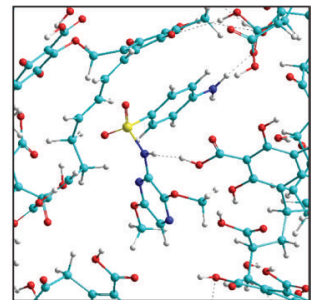

(c)

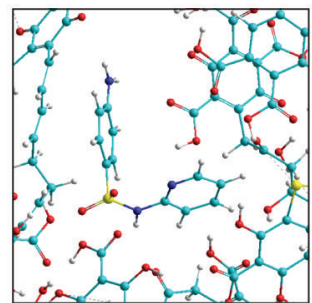

(d)

FIGURE 5: Ball plot of (a) a DOM trimer with enlargements of the sections with the trapped sulfonamides (b) SAA, (c) SDT, and (d) SPY.

of $\mathrm{O}, \mathrm{N}$, and $\mathrm{S}$ functional groups on the alkyl aromatic skeleton, was assumed to represent the complex structure of soil organic sorbents. The polar DOM-trimer model offers appropriate void areas for sorption processes of the polar sulfonamides.
Running extended MM+ calculations for geometry optimization (or energy minimization), the antibiotic-DOM trimer complexes resulting from sulfonamide sorption in voids of the DOM trimer were modeled and are listed in Table 4. A Polak-Ribiere conjugate gradient was used in 
vacuo and $>30,000$ iterative steps were needed to minimize the energy gradient of each model to $\leq 0.04 \mathrm{~kJ} \mathrm{~mol}^{-1}$. The main mechanisms for the binding of SAA, SPY, and SDT are presented in Figure 5. The DOM trimer is characterized with the largest van der Waals volume $\left(2510.76 \mathrm{~nm}^{3}\right)$ and the largest total potential energy of $10,414.42 \mathrm{~kJ} \mathrm{~mol}^{-1}$. As expected, the average molecular weights of the trapped antibiotics contributed $<1 \%$ to the molecular weight of the antibiotic-DOM trimer complex.

The antibiotic-DOM trimer complexes are displayed in Figures 5(b)-5(d), where the guest molecules are entrapped in voids of the organic matter. It is shown that hydrogen bonds are formed and that torsion of the sulfonamide molecules is energetically favorable. Thus, the contribution of both specific and hydrophobic binding forces to the sorption of sulfonamides is indicated as concluded from the experimental data and as it was previously reported for the modeling of humic complexes with diethyl phthalate [16]. The $\mathrm{MM}+$ calculations of the van der Waals forces demonstrated that dipole-dipole interactions are crucial for the sorption of the three sulfonamides to the DOM trimer structure (Table 4). Both hydrogen bonds and nonbonded van der Waals interactions are stable at the final conformation; the MM+ calculated electrostatic forces were highly negative and ranged between -5544.30 and $-5631.83 \mathrm{~kJ} \mathrm{~mol}^{-1}$.

The MM+ calculations resulted in solvent-accessible surface areas of $1200.22 \mathrm{~nm}^{2}$ for the DOM trimer structure and for the complexes with the sulfonamides of between $534.34 \mathrm{~nm}^{2}$ (SAA) and $553.05 \mathrm{~nm}^{2}$ (SDT). Stabilization energies for the three complexes were calculated by subtracting the total energy of the host molecule from the total energy of the antibiotic-DOM trimer complex and were $-198.60 \mathrm{~kJ} \mathrm{~mol}^{-1}$ for SAA, $-48.51 \mathrm{~kJ} \mathrm{~mol}^{-1}$ for SPY, and $-31.76 \mathrm{~kJ} \mathrm{~mol}^{-1}$ for SDT (Table 4). However, the modeled sorption energies did not follow the sequence of the experimental sorption parameters (Table 2). It is assumed that additional sorption mechanisms such as electron and proton transfer substantially contribute to the sorption of sulfonamides but are not covered by $\mathrm{MM}+$ calculations [22]. The authors in [34] reported that negative charges at the pyrimidine nitrogen atom of sulfonamide molecules are stable even when the molecule should exist as the neutral species.

\section{Conclusions}

Model sorbents with a reduced molecular complexity such as the VEO used in this study are suited to identify specific binding sites. Here it was shown that, in addition to $\pi-\pi$ interactions with the aromatic ring the phenolic, aldehyde and methoxyl moieties are possibly preferred moieties for sulfonamide sorption. However, differences to the sorption to a more complex soil-extracted HA existed, and stronger sorption of sulfonamides to the latter was attributed to a contribution of additional ketonic, enolic, alcoholic, and $\mathrm{N}$-alkylic functionalities. Additionally, HA offers voids and pores for sorbate entrapment. The sorption of the different cationic, neutral, and anionic sulfonamide species differed, and sequences changed among sulfonamides depending on the specific speciation. Furthermore, competition of phosphorus with anionic species for sorption sites was indicated by the results. Clear sorption hysteresis was determined, while the nonextractable fraction of the sulfonamides was minor with in general $<1 \%$ of the spiking concentration. Hydrogen bond donor/acceptor properties of the sulfonamides appeared to be one relevant property explaining different sorption among compounds. With $\mathrm{MM}+$ calculations, it was confirmed that, in addition to hydrophobic partitioning, hydrogen bonds and dipole-dipole interactions are among the relevant sorption mechanisms of sulfonamides. It is expected that in future the combination of both experimental and computational sorption data will be used more routinely for an in-depth understanding of xenobiotic sorption in soil.

\section{Acknowledgments}

This project was financially supported by the Deutsche Forschungsgemeinschaft (DFG Th 678/4-1/2). The authors thank P. Leinweber for support and M.-O. Aust for help with the analyses.

\section{References}

[1] A. B. A. Boxall, L. A. Fogg, P. A. Blackwell, P. Kay, E. J. Pemberton, and A. Croxford, "Veterinary medicines in the environment," Reviews of Environmental Contamination and Toxicology, vol. 180, pp. 1-91, 2004.

[2] K. Kumar, S. C. Gupta, Y. Chander, and A. K. Singh, "Antibiotic use in agriculture and its impact on the terrestrial environment," Advances in Agronomy, vol. 87, pp. 1-54, 2005.

[3] S. Thiele-Bruhn, "Pharmaceutical antibiotic compounds in soils-a review," Journal of Plant Nutrition and Soil Science, vol. 166, no. 2, pp. 145-167, 2003.

[4] A. A. MacKay and B. Canterbury, "Oxytetracycline sorption to organic matter by metal-bridging," Journal of Environmental Quality, vol. 34, no. 6, pp. 1964-1971, 2005.

[5] W. Lertpaitoonpan, S. K. Ong, and T. B. Moorman, "Effect of organic carbon and $\mathrm{pH}$ on soil sorption of sulfamethazine," Chemosphere, vol. 76, no. 4, pp. 558-564, 2009.

[6] T. L. Ter Laak, W. A. Gebbink, and J. Tolls, "The effect of pH and ionic strength on the sorption of sulfachloropyridazine, tylosin, and oxytetracycline to soil," Environmental Toxicology and Chemistry, vol. 25, no. 4, pp. 904-911, 2006.

[7] J. Gao and J. A. Pedersen, "Adsorption of sulfonamide antimicrobial agents to clay minerals," Environmental Science and Technology, vol. 39, no. 24, pp. 9509-9516, 2005.

[8] S. T. Kurwadkar, C. D. Adams, M. T. Meyer, and D. W. Kolpin, "Effects of sorbate speciation on sorption of selected sulfonamides in three loamy soils," Journal of Agricultural and Food Chemistry, vol. 55, no. 4, pp. 1370-1376, 2007.

[9] S. Thiele-Bruhn, T. Seibicke, H. R. Schulten, and P. Leinweber, "Sorption of sulfonamide pharmaceutical antibiotics on whole soils and particle-size fractions," Journal of Environmental Quality, vol. 33, no. 4, pp. 1331-1342, 2004.

[10] J. Gao and J. A. Pedersen, "Sorption of sulfonamide antimicrobial agents to humic acid-clay complexes," Journal of Environmental Quality, vol. 39, no. 1, pp. 228-235, 2009. 
[11] M. Kahle and C. Stamm, "Sorption of the veterinary antimicrobial sulfathiazole to organic materials of different origin," Environmental Science and Technology, vol. 41, no. 1, pp. 132138, 2007.

[12] M. Förster, V. Laabs, M. Lamshöft et al., "Sequestration of manure-applied sulfadiazine residues in soils," Environmental Science and Technology, vol. 43, no. 6, pp. 1824-1830, 2009.

[13] J. M. Bollag, J. Dec, and P. M. Huang, "Formation mechanisms of complex organic structures in soil habitats," Advances in Agronomy, vol. 63, pp. 237-266, 1997.

[14] J. M. Suflita and J. M. Bollag, "Polymerization of phenoliccompounds by a soil-enzyme complex," Soil Science Society of America Journal, vol. 45, pp. 297-302, 1981.

[15] H. R. Schulten and M. Schnitzer, "Chemical model structures for soil organic matter and soils," Soil Science, vol. 162, no. 2, pp. 115-130, 1997.

[16] H. R. Schulten, M. Thomsen, and L. Carlsen, "Humic complexes of diethyl phthalate: molecular modelling of the sorption process," Chemosphere, vol. 45, no. 3, pp. 357-369, 2001.

[17] J. D. Kubicki, "Molecular mechanics and quantum mechanical modeling of hexane soot structure and interactions with pyrene," Geochemical Transactions, vol. 1, pp. 41-46, 2000.

[18] H. Sakurai and T. Ishimitsu, "Microionization constants of sulphonamides," Talanta, vol. 27, no. 3, pp. 293-298, 1980.

[19] S. Thiele-Bruhn and M.-O. Aust, "Effects of pig slurry on the sorption of sulfonamide antibiotics in soil," Archives of Environmental Contamination and Toxicology, vol. 47, no. 1, pp. 31-39, 2004.

[20] H. R. Schulten, "Interactions of dissolved organic matter with xenobiotic compounds: molecular modeling in water," Environmental Toxicology and Chemistry, vol. 18, no. 8, pp. 1643-1655, 1999.

[21] M. Sander, Y. Lu, and J. J. Pignatello, "A thermodynamically based method to quantify true sorption hysteresis," Journal of Environmental Quality, vol. 34, no. 3, pp. 1063-1072, 2005.

[22] K. I. Ramachandran, G. Deepa, and K. Namboori, Computational Chemistry and Molecular Modeling-Principles and Applications, Springer, Berlin, Germany, 2008.

[23] H. R. Schulten and P. Leinweber, "Thermal stability and composition of mineral-bound organic matter in density fractions of soil," European Journal of Soil Science, vol. 50, no. 2, pp. 237-248, 1999.

[24] R. E. Green and S. W. Karickhoff, "Sorption estimates for modeling," in Pesticides in the Soil Environment: Processes, Impacts, and Modeling, H. H. Cheng, Ed., pp. 79-101, Madison, Wis, USA, 1990.

[25] S. Hyun and L. S. Lee, "Quantifying the contribution of different sorption mechanisms for 2,4-dichlorophenoxyacetic acid sorption by several variable-charge soils," Environmental Science and Technology, vol. 39, no. 8, pp. 2522-2528, 2005.

[26] Y. J. Wang, R. J. Sun, A. Y. Xiao, S. Q. Wang, and D. M. Zhou, "Phosphate affects the adsorption of tetracycline on two soils with different characteristics," Geoderma, vol. 156, no. 3-4, pp. 237-242, 2010.

[27] R. P. Schwarzenbach, P. M. Gschwend, and D. M. Imboden, Environmental Organic Chemistry, Wiley Interscience, New York, NY, USA, 2003.

[28] E. Barriuso and W. C. Koskinen, "Incorporating nonextractable atrazine residues into soil size fractions as a function of time," Soil Science Society of America Journal, vol. 60, no. 1, pp. 150-157, 1996.

[29] P. G. Hatcher, J. M. Bortiatynski, R. D. Minard, J. Dec, and J. M. Bollag, "Use of high-resolution ${ }^{13} \mathrm{C}$ NMR to examine the enzymatic covalent binding of ${ }^{13} \mathrm{C}$-labeled 2,4-dichlorophenol to humic substances," Environmental Science and Technology, vol. 27, no. 10, pp. 2098-2103, 1993.

[30] L. Wang, R. Govind, and R. A. Dobbs, "Sorption of toxic organic compounds on wastewater solids: mechanism and modeling," Environmental Science and Technology, vol. 27, no. 1, pp. 152-158, 1993.

[31] S. Altfelder, T. Streck, and J. Richter, "Nonsingular sorption of organic compounds in soil: the role of slow kinetics," Journal of Environmental Quality, vol. 29, no. 3, pp. 917-925, 2000.

[32] A. Bhandari, "Binding of 4-monochlorophenol to soil," Environmental Science and Technology, vol. 30, no. 7, pp. 23052311, 1996.

[33] R. Sutton and G. Sposito, "Molecular simulation of humic substance-Ca-montmorillonite complexes," Geochimica et Cosmochimica Acta, vol. 70, no. 14, pp. 3566-3581, 2006.

[34] G. Huschek, D. Hollmann, N. Kurowski, M. Kaupenjohann, and H. Vereecken, "Re-evaluation of the conformational structure of sulfadiazine species using NMR and ab initio DFT studies and its implication on sorption and degradation," Chemosphere, vol. 72, no. 10, pp. 1448-1454, 2008. 

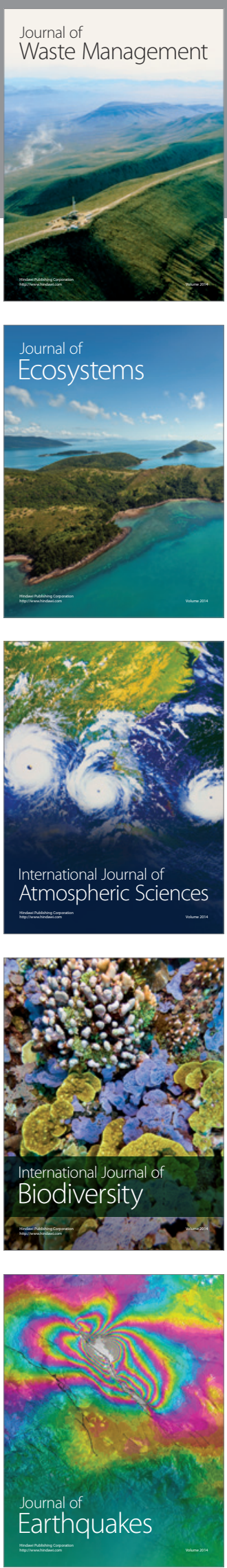
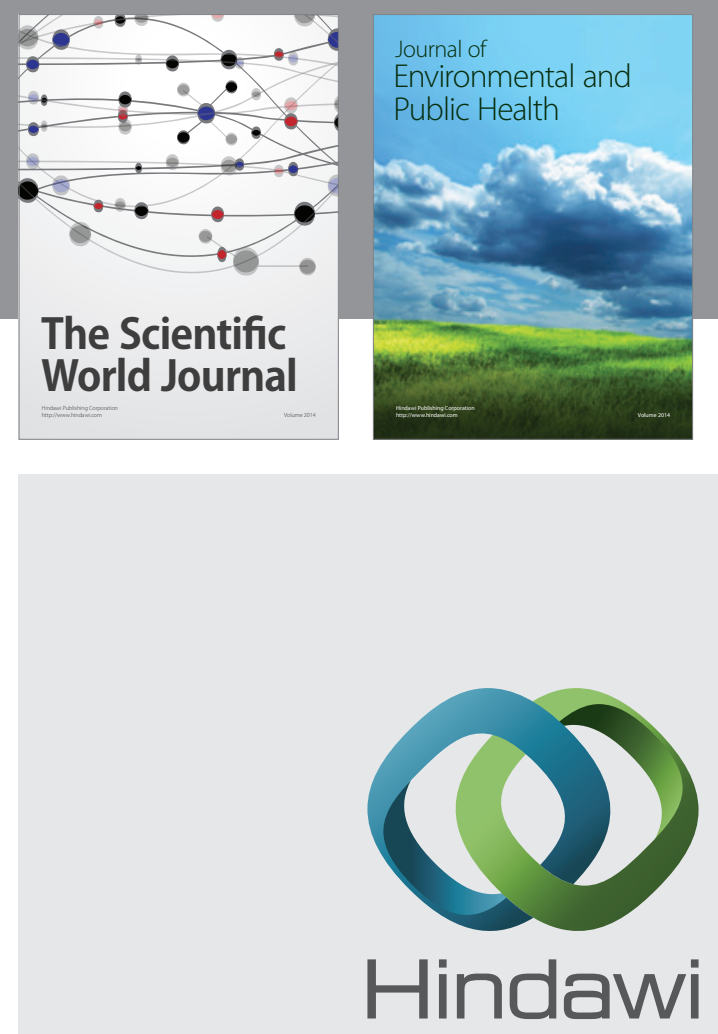

Submit your manuscripts at

http://www.hindawi.com
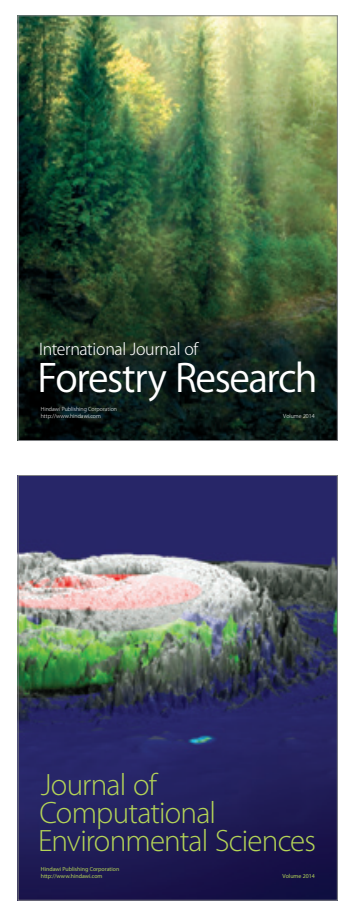
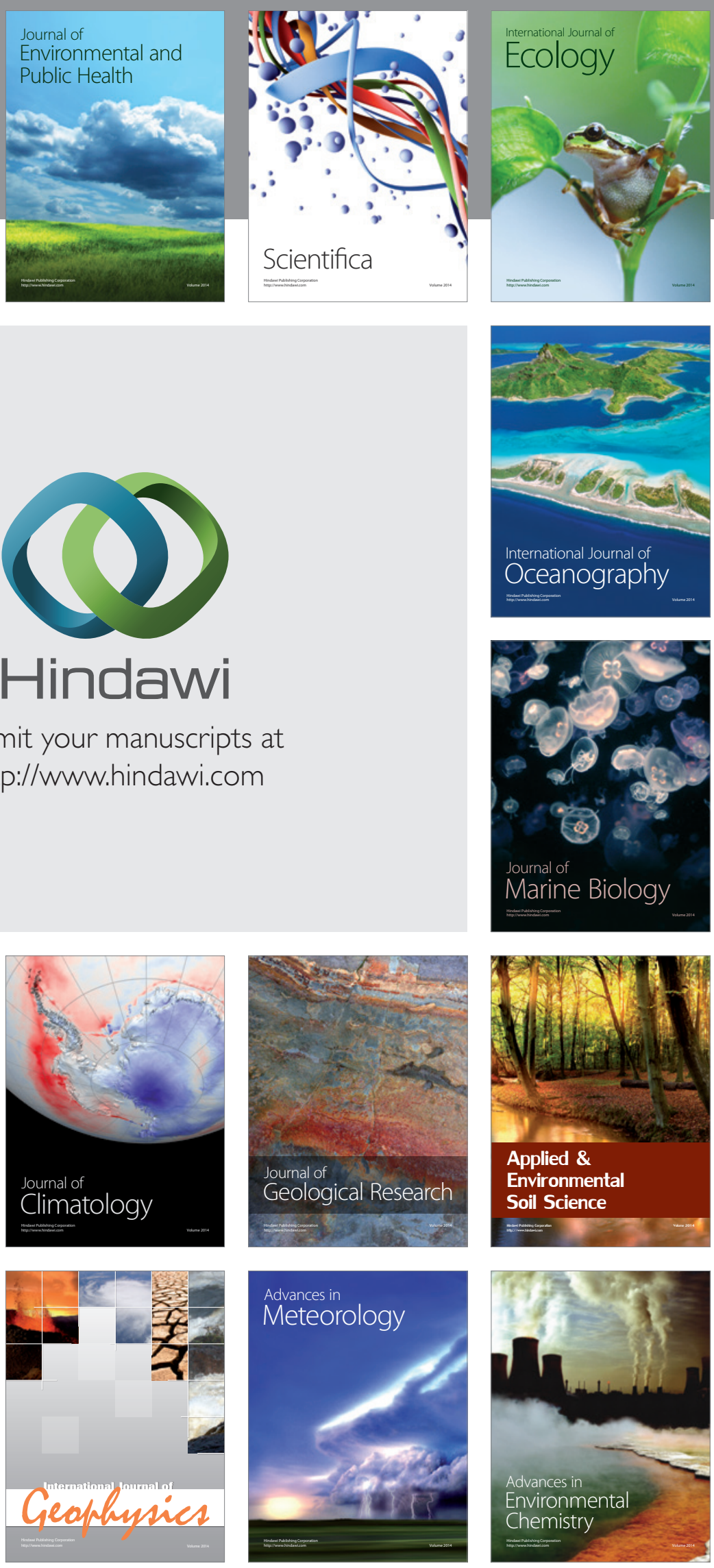